\title{
Why are European countries diverging in their unemployment experience?*
}

\author{
Gilles Saint-Paul
}

February 28, 2004

\section{Introduction}

Unemployment has been high in many European countries for now more than thirty years. At the same time it has reached very low levels in the Unites States, and furthermore growth has been faster there since 1995. These developments have brought about a sense of 'decline' in many European countries and one may ask whether Europe will eventually solve its unemployment problem and converge again to the US, or whether the divergence will continue and relegate Europe in a lower category.

This paper takes a look at the evolution of unemployment and labor market institutions in European countries. A key finding (section 2) is that of divergence within Europe, where some countries have managed to reduce unemployment substantially, while others seem to be stuck at high unemployment levels. There is some evidence that the countries who got out of the unemployment problem implemented a number of labor market reforms. The other countries have followed a more contradictory path, having sometimes 'positive' reforms and sometimes 'negative' ones. In section 3 I look at alternative, quantitative measures of competition in labor markets. While these measures do

*This paper was prepared for the Journal of Economic Perspectives. I am grateful to Olivier Blanchard for useful comments. 
not match the observed evolutions of unemployment and labor market regulations - which suggests there may be problems with the data or with the true impact of these reforms - they do not provide grounds for optimism in those countries that still experience high unemployment, with the potential exception of Italy. I then discuss - section 4 - how the political economy approach may offer some insight about potential obstacles to labor market flexibility, and how political support against reforms may be sustained by, and reinforce as well, ideologies and views of the economy that run against useful reforms. In section 5 , some perspectives are offered about how to explain which countries were successful and which were not, although there are more research directions than firm conclusions. Section 6 concludes.

\section{What have we learned?}

\subsection{Basic facts}

Unemployment had been historically very low in most European countries during the sixties. However, it rose sharply in the early seventies, and in many countries has not fallen back to its previous level (Table 1).

While unemployment increased everywhere in the early seventies, since the mid-eighties there has been a diverging pattern. Countries can be split between those that apparently managed to reduce their unemployment rates back to a low level, and those where it remains high and persistent. These includes, in particular, the three largest continental economies, France, Italy, and Germany. As for Spain, unemployment has fallen sharply in recent years, but that was from a pathologically high level, and it remains higher there than in most other European countries, and certainly much higher than in 1970. The only big country that seems to have escaped from persistent long-term unemployment is the UK. Unemployment seems to have fallen in a number of other small countries: Ireland, the Netherlands, Denmark, and Portugal. Scandinavian countries escaped the rise in unemployment of the seventies, but experienced 
a sharp increase in the nineties, due to external macroeconomic shocks. Since then, unemployment has fallen back to secular low levels in Norway and Sweden, but not Finland.

The individual experience is therefore quite diverse, and in some sense one may no longer talk of a common European unemployment problem. One should also point out that this divergence cannot be explained by cross-country differences in the definition of unemployment or in the use of disguised unemployment schemes such as (some) active labor market policies, pre-retirement, and so on. For example, France has a high unemployment rate but also one of the highest fraction of the workforce in relief jobs or early retirement, and the lowest work week for full-time employed workers. ${ }^{1}$ Spain has a high unemployment rate and also a very low participation rate. The popular view that a lot of unemployment in the Netherlands is hidden as disability is not inaccurate, but it does not explain the fall in unemployment there: the fraction of workers on disability benefits has also fallen. Also, the correlation across countries between unemployment and participation in 2000 was -0.5 , so countries with high unemployment tend to have lower participation. And the cross-country correlation between hours worked per employee and unemployment is essentially zero. ${ }^{2}$

\footnotetext{
${ }^{1}$ See for example, OECD Labor force statistics (2003)

${ }^{2}$ These correlations were computed using the OECD Economic outlook database.
} 


\begin{tabular}{llllll}
\hline \hline & \multicolumn{7}{l}{ Unemployment rate } \\
\hline Country & 1970 & 1980 & 1990 & 1995 & 2000 \\
Austria & 1.6 & 1.6 & 4.7 & 5.9 & 5.8 \\
Belgium & 1.9 & 7.9 & 8.7 & 12.9 & 10.6 \\
Denmark & 1.3 & 6.9 & 9.4 & 10.2 & 5.8 \\
Finland & 1.9 & 4.7 & 3.2 & 15.4 & 9.1 \\
France & 2.5 & 6.2 & 8.9 & 11.6 & 10.3 \\
Germany & 0.6 & 3.2 & 6.2 & 8.1 & 8.7 \\
Greece & 4.2 & 2.8 & 7.0 & 10.0 & 10.9 \\
Ireland & 5.6 & 7.0 & 12.9 & 12.2 & 5.0 \\
Italy & 4.0 & 5.6 & 9.1 & 11.7 & 11.2 \\
Netherlands & 0.9 & 4.0 & 6.0 & 7.1 & 3.2 \\
Norway & 1.4 & 1.7 & 5.2 & 4.9 & 3.8 \\
Portugal & 5.8 & 9.5 & 4.7 & 7.2 & 4.3 \\
Spain & 2.7 & 10.9 & 15.7 & 22.7 & 14.0 \\
Sweden & 1.5 & 2.0 & 1.7 & 7.7 & 4.5 \\
United Kingdom & 2.4 & 6.1 & 5.9 & 8.6 & 6.0 \\
\hline \hline
\end{tabular}

Table 1 - The evolution of unemployment rates in the European Union

At the beginning of the current century, therefore, Europe can be split into two clubs: a low-unemployment club, which includes Austria, Denmark, Ireland, the Netherlands, Norway, Portugal, Sweden, Switzerland, and the United Kingdom, and a high-unemployment club, made of Belgium, France, Germany, Greece, Italy, and Spain.

\section{$2.2 \quad$ Potential explanations}

This divergence among European countries that occurred in the nineties - with some countries being able to reduce their unemployment rate at remarkably low levels and others being stuck at high levels - is potentially a quite useful experiment if one wants to know the underlying causes of unemployment. If there is something that these countries did and others did not, then there is a presumption that one has uncovered a cause of unemployment.

When unemployment started to increase in the 1970s, at that time it was widely believed that the increase was due to the first oil shock, an adverse aggregate supply shock (see Bruno and Sachs (1985)). Then came the second oil 
shock, contractionary monetary policies in the eighties, so that at each point in time there was an "immediate cause" that could be formulated in terms of short-run fluctuations. Yet in the longer run unemployment failed to return to its initial level even though the oil shocks have been almost entirely offset and nominal prices should adjust to bring unemployment back to its equilibrium level Therefore, some sort of consensus emerged that high unemployment in Europe was in fact due to labor market rigidities, in other words to a higher equilibrium rate than in the sixties. These rigidities consist of a set of institutions that increase the equilibrium rate of unemployment by boosting the incumbent employee's bargaining power in wage setting (such as minimum wages, work rules or employment protection), or their fallback options (such as the level and duration of unemployment benefits and other welfare payments). Standard theory states that in order to offset these factors and to bring back wages to a level compatible with productivity, the equilibrium rate of unemployment must go $\mathrm{up}^{3}$.

In order to be valid, this hypothesis must pass two tests. First, is there a sense in which rigidities have increased or become more relevant during the high unemployment period as compared to the sixties? Second, does it help to understand the subsequent divergence? My answer to both questions is a qualified yes.

A recent paper by Nickell (2003) provides a concise and synthetic assessment of the evolution of labor market institutions in Europe and their impact on unemployment. It shows that:

(i) In most countries, labor market are more rigid now, along a number of dimensions, than in the sixties, suggesting that the unemployment problem is unlikely to go away by itself.

(ii) Countries that managed to reduce unemployment in the nineties did so by implementing some wage moderation mechanisms, often through a compre-

\footnotetext{
${ }^{3}$ See Layard et al. (1990) for an exposition.
} 
hensive reform package, i.e. progress was made on a number of aspects.

(iii) Countries that did not, did not implement significant reforms and have kept rigid labor market institutions. Or, they increased flexibility along a few dimensions but reduced it along many others.

Thus it is excessive, as some authors do, to claim that institutions are not responsible for the rise in European Unemployment, because European labor markets were already rigid in the sixties. In fact, a number of indices of labor rigidity have gone up. The data in Nickell (2003) show a sharp increase in unemployment benefits in virtually all European countries except the UK between 1960 and 1999; indices of employment protection legislation have gone up in Austria, Belgium, France, Germany, Ireland, Portugal, Sweden, and the UK. They have fallen (but only slightly) in Finland, Italy, the Netherlands, Norway, and Spain. Finally, taxes on labor have gone up everywhere. Thus it is unlikely that unemployment is only due to shocks and different persistent responses to these shocks (See Blanchard and Wolfers, 2000 for an analysis); at a minimum these shocks should affect the political dynamics of institutions so as to permanently change them. It also contradicts the view that the rise in European unemployment is entirely explained by a shift from a "good" equilibrium to a "bad" one under constant institutions. Such a shift is possible, but then the "good" equilibrium itself is likely to have deteriorated. ${ }^{4}$

Going back to the divergence of the nineties, between 1980 and 2000, in France, benefit duration lengthened, union coverage went up, coordination of wage setting went down, and employment protection became stricter. In Italy, the replacement rate went up, and so did labor taxes. In Germany, benefit duration lengthened. In contrast, the Netherlands experienced an increase in the strictness of unemployment benefit administration, better coordination in wagesetting (the Wassenaar agreement), lower labor taxes and less strict employment protection. The UK has a less clear pattern, since benefit duration went up,

\footnotetext{
${ }^{4}$ See for example Blanchard and Summers (1988), Saint-Paul (1995) for some theoretical arguments.
} 
but had many changes that went in the direction of lower unemployment: lower replacement rates, stricter benefit administration, much reduced union coverage, lower union density, lower labor taxes. Ireland experienced similar institutional changes as the UK (Table 2). It is the country where unemployment has fallen most rapidly in the second half of the nineties, and during that period, all institutional indicators went in the direction of lower unemployment, except UB duration, whose lengthening was probably innocuous (as in the UK) in light of the sharp fall in average replacement rations, and employment protection, which remained untouched.

\begin{tabular}{lllll}
\hline \hline Indicator & $65-72$ & $80-87$ & $1988-95$ & 2000 \\
\hline Unemployment rate & 5.6 & 7.0 & 12.9 & 5.0 \\
Unemployment benefits & 24 & 50 & 40 & 35 \\
UB Duration & 0.78 & 0.4 & 0.39 & 0.77 \\
Union density & 51 & 56 & 51 & 43 \\
Coordination in wage setting & 2 & 2 & 2 & 3 \\
Employment protection & 0.19 & 0.5 & 0.5 & 0.5 \\
Labour taxes & 30 & 37 & 41 & 33 \\
\hline \hline
\end{tabular}

Table 2 - Institutional changes in Ireland (Source: Nickell (2003))

Therefore, the evidence supports the traditional view that rigidities that reduce competition in labor markets are typically responsible for high unemployment. Reducing these rigidities globally seems to work. But it is much less clear how much would be gained, if anything, by increasing flexibility along one dimension only. In other words, we are not sure how much unemployment unions, or employment protection, or minimum wages are responsible for, but we know that altogether they substantially increase it. That is probably due to a lack of reliable data. But the evidence will not convince opponents of that traditional view that it is valid, and should lead its partisans to advocate a comprehensive reform package rather than a reform of a specific institution.

If one takes unemployment benefits, for example, there is a general tendency for replacement ratios to fall during the nineties; but there is no significant correlation across European countries between the extent of the fall and the change unemployment: the correlation is indeed positive, as expected 
$(+0.37)$ but not significant ${ }^{5}$. And, in a cross-section of countries, one observes all possible cases: high unemployment/high benefits (Spain), high unemployment/low benefits (Italy), low unemployment/high benefits (Sweden), low unemployment/low benefits (UK). This is somewhat paradoxical in light of the theory, which predicts that the unemployment benefit replacement ratio is the most robust determinant of equilibrium unemployment. What researchers have found, though, is a significant positive association between benefit duration and unemployment duration ${ }^{6}$. This could not be true, obviously, if benefit levels did not matter too. It may simply be that numerous data problems (such as omitted variables) are filtered out when one looks at unemployment duration vs. benefit duration instead of levels.

Another intriguing aspect of the experience of the 1990s is that most of the gains, in the low unemployment club, were realized during the expansionary phase of the second half of the decade. During that period unemployment fell everywhere but returned to the previous trough in the high unemployment club, while it typically fell much below in the low unemployment club. From a layman perspective, this seems to make sense: structural reform is useless if the jobs are not there. But, from an economist's perspective, that is much harder to understand. First, we know that plenty of jobs are created during recessions ${ }^{7}$. Second, we typically think that the relationship between labor market tightness and wage (or inflationary) pressure is convex, so that the increase in labor demand triggered by structural reforms should create more jobs in recessions than in expansions.

\section{Some more evidence: the evolution of rents}

The preceding discussion suggests that countries that still experience high unemployment have had timid, "stop-and-go", labor market reform strategies.

\footnotetext{
${ }^{5}$ Source: DICE database.

${ }^{6}$ See for example Bean (1994).

${ }^{7}$ Davis, Haltiwanger, and Schuh (1996).
} 
However, looking at actual institutional changes has some shortcomings in such cases. First, it may well be that the "good" reforms outweigh the "bad" ones quantitatively. Second, product market deregulation has proceeded in all European countries and one may believe that it contributes to reducing worker rents and the natural rate of unemployment (see Blanchard and Philippon (2003) for a recent discussion), even in those countries that did not implement significant labor market reforms. One may thus want to look at alternative measures of the degree of competition in labor markets in Europe. For this reason, it may be useful to pursue a different approach and look at direct quantitative measures of the labor market's competitiveness. This is what is attempted in Saint-Paul (2004), who tries to measure labor market competitiveness by constructing indices of the employed's rent, i.e. the welfare difference between an employed workers and a similar unemployed worker. The drawback of that approach is that it does not tell us which reforms have been implemented; workers' rents may fall under a number of labor market reforms, product market reforms or the sheer pressure of international competition. On the other hand, it gives us an idea of the evolution of the true degree of competition in labor markets. It avoids misclassifying a policy change or taking serious one which turns out to have only second-order effects on actual labor market flexibility, or which, for some reason, is not enforced.

To measure rents, Saint-Paul (2004) uses two different approaches. The first one exploits variation across industries of wages. This empirical regularity has been much studied in the eighties and nineties, under the impulse of Krueger and Summers (1988). As argued by these authors, there are good reasons to believe that these differentials capture worker rents. Therefore, we hope to learn something about the evolution over time of labor market rents in a number of European countries by looking at how the estimated coefficients of a wage equation, in an individual data set, on industry dummies evolve. If rents are falling over time, then we expect the dispersion in these coefficients across sectors 
to be falling too: In a rent-free economy, all of them would be equal to zero. In a variant of that exercise, one may also look at wage differentials across firm size categories instead of industries. The second approach, as in Cohen (1999) tries to estimate a dynamic process for individual transitions between employment and unemployment, and to use the estimated coefficients to compute the present discounted value of being employed and the present discounted value of being unemployed for any given category of worker. The difference between the two gives us the total rent of the employed. That approach is less likely than the other one to be biased by systematic sorting of workers with better unobservable characteristics into high-wage sectors; on the other hand it is more vulnerable to business cycles fluctuations.

\begin{tabular}{lllll}
\hline \hline Country & Interindustry premium & Size premium & U/E differential & Unemployment club \\
\hline Denmark & $=$ & $=$ & $=-$ & $\mathrm{L}$ \\
Netherlands & $=$ & + & $=-$ & $\mathrm{L}$ \\
Belgium & $=$ & - & - & $\mathrm{H}$ \\
France & $=$ & - & $=-$ & $\mathrm{H}$ \\
Ireland & - & - & - & $\mathrm{L}$ \\
Italy & $=$ & - & $=-$ & $\mathrm{H}$ \\
Spain & $=$ & $=$ & + & $\mathrm{H}$ \\
Portugal & $=$ & $=$ & + & $\mathrm{L}$ \\
Austria & + & $=$ & - & $\mathrm{L}$ \\
Finland & $+=$ & $=$ & - & $\mathrm{H}$ \\
\hline \hline
\end{tabular}

Table 3 - Evolution of different concepts of the employed's rent in various countries between 1994 and 2000

(Source: Saint-Paul, 2004)

Performing that exercise, we get mixed results, that are summarized in Table 3: most coefficients do not fall over time, and therefore there is no robust presumption that rents have fallen in the 1990s. There is no systematic association between having falling rents according to a variety of measures and being a member of the low unemployment club. Rents seem to have increased in Portugal and Ireland, two low unemployment countries, and fallen in Italy, a high unemployment one. On the other hand, the sharp fall in unemployment in Ireland does seem to be associated with reduced rents. 
That lack of association between measured rents and the evolution of unemployment may be due to several factors. First, there may simply exist long lags between a reduction in rents and the induced fall in unemployment. Second, wage pressure may be reduced, and so would equilibrium unemployment, if the workers' outside options in bargaining, rather than their rents, fall. That is what a reduction of unemployment benefits typically achieves. Thus, rents do not provide an overall picture, but they tell us something about the extent to which insiders shelter themselves from competition with outsiders. This in turn has relevance, as discussed in the next section, for long-term reform prospects: reforms are easier if rents are smaller. Table 3 suggests that the only countries where there are signs that rents have fallen are Ireland and Italy. If one takes these arguments seriously, that would suggest that reforms could accelerate in the future.

So, the findings do not generally confirm the evidence in the previous section. That may be due to data problems or suggest that labor market reforms in a number of countries (except Ireland) have not in fact increased competition in labor markets. On the other hand, (except perhaps in Italy), there is no sign of increased labor market competition in countries of the high unemployment club, in contradiction with the view that it could be significantly affected by developments outside the labor market, such as product market deregulation or greater international capital mobility.

\section{Obstacles to reform}

Since a number of countries seem to have failed to implement labor market reforms, one should discuss the obstacles to reform. This is what we do in this section. 


\subsection{Political economy}

One key obstacle to labor market reform in Europe is that there exists powerful constituencies of incumbent employees that may block reform. This is the phenomenon I have analyzed in my previous work ${ }^{8}$. Such an approach may explain why government have little incentives to implement the proper reforms in order to fight unemployment.

\subsubsection{The basic messages of the political economy approach}

Essentially, political support for labor market rigidities will arise when a sufficiently large fraction of the workforce earn rents, when these rents can be enhanced by manipulating market outcomes through institutions, so as to redistribute in favor of the most powerful groups of workers (referred below as "incumbent employees" or "insiders"), and when alternative, less distortionary means of redistributions are not feasible (one reason being that to implement them one might have to give transfers to some workers but not all, violating the anonymity of public policy). Thus, we expect to observe labor market rigidities, the greater the effect of labor market regulations on wages, and the more difficult or costly traditional redistributive tools are.

Alternatively, one may view these mechanisms as follows: Manipulating labor market institutions by means of voting and lobbying activities is a way for incumbent employees to circumvent the collective action problem and achieve monopoly power at the economy-wide level. They achieve that at the expense of other social groups. While many people tend to think of labour issues as a conflict between labor and capital, international capital mobility implies that capital adjusts very elastically to changes in its rate of return, so that labor market rigidities only redistribute between capitalists and workers in the short run. In the medium run, they redistribute between different categories of workers. For example, wage rigidity would benefit employed "unskilled", or "moderately

\footnotetext{
${ }^{8}$ See references at the end of the paper.
} 
skilled" workers, at the expense of skilled ones, a complementary input whose marginal product falls when employment of less skilled workers is reduced. Similarly, rigidities that have more effect on one sector than another may redistribute in favor of workers in that sector and at the expense of workers in other sectors, by raising the relative price of that sector and then the wages of its workers.

A number of key predictions of the political economy approach, as spelled out in Saint-Paul (2000), are:

- Labor market institutions will be determined more by the interests of employed workers than unemployed ones. Consequently, they will be designed to achieve neither full employment nor social welfare. They will imply more wage rigidity and more employment protection than socially optimal $^{9}$. Labor market reforms are politically viable only to the extent that they are designed so as to preserve their interests.

- Role of economic environment: the gains and losses to the insiders from labor market institutions depend on the economic environment. For example, a greater elasticity of labor demand reduces the value to them of institutions (such as work rules, etc.) which allow to improve their bargaining position in the wage formation process. That is, when elasticity is greater, regulation does a poorer job at increasing the wages of incumbent employees - a given wage rise is more costly in terms of employment - and there is less support for it (just like a monopoly would like to charge a lower price). Greater exposure to unemployment increases the value to the employed of reforms that boost job creation; conversely, if insiders are extremely sheltered from job loss, they will not gain from such reforms. The

\footnotetext{
${ }^{9}$ They may imply either more or less generous unemployment benefits than socially optimal, depending on whether the insurance effects of unemployment benefits domnate their effects on wage formation (See Saint-Paul, 2000, ch. 5). Note also that the socially optimal degree of employment protection need not be zero if there exists microeconomic frictions in the labor market and if there is a limited set of policy instruments to cope with them (See Saint-Paul, 2000, ch. 4).
} 
more exposed the employed, the more they take into account the interest of the unemployed in their political decisions, since they have a greater probability of becoming unemployed in the future. Greater inequality also affects the political support for labor market institutions; for example it may reduce the support for wage compression across workers of different skills by making it too costly in terms of unemployment. ${ }^{10}$

- Status-quo bias: some labor market rigidities create their own constituency. This leads to status-quo bias: an institution has more support if it already exists than if it is yet to be put in place. One example is employment protection: it maintains a number of workers in unproductive jobs that would not exist absent employment protection. If employed workers earn rents, an employed's welfare is greater than a similar unemployed's welfare, those in these jobs will favor maintaining employment protection as it is costly for them to lose their jobs. ${ }^{11}$ Status-quo bias implies that there may be path dependence in labor market regulations; path-dependence is stronger, the greater the rents earned by incumbent employees.

- Politico-economic complementarities: the existence of one institution often creates political support for another institution ${ }^{12}$. Employment protection helps workers maintain their rents by reducing exposure to unemployment. Assume there exists an institution that increases the wages of some categories of workers, and therefore creates rents for these workers. Then the political support for employment protection is greater if that institution is present than if it is not. Conversely, if employment protection exists, workers are less exposed to job loss. This makes them more likely to support any institution which raises labor costs, for they are less likely

\footnotetext{
${ }^{10}$ See Saint-Paul (2000), ch.3.

${ }^{11}$ See Saint-Paul (1997, 2000 ch.6, 2002).

${ }^{12}$ Complementarities may also arise from other economic mechanisms, see Orszag and Snower (1998).
} 
to lose their jobs as a result. ${ }^{13}$ Empirically, reform packages seem to have been more efficient than isolated reforms. Countries that have managed to reduce unemployment substantially, such as Britain or the Netherlands, have implemented a number of reforms; in contrast, isolated reforms such as the attempted reduction of minimum wages for youth in France in 1994, have often failed. This squares well with the view that there exists politico-economic complementarities.

\subsubsection{An illustration: reducing firing costs through temporary con- tracts}

A nice illustration of how political constraints shape labor market policy, is the role of temporary contracts and similar marginal work arrangements, in European reforms of employment protection legislation. Most of these reforms have been done in a "two-tier" fashion, by liberalizing the labor market at the margin. ${ }^{14}$ Typical is the deregulation of the use of temporary contracts in Spain, France, Italy, Portugal, and Germany. By leaving the insider's employment protection unchanged, the government can buy their political support for the reform. Furthermore, it seems that these reforms typically take place at "bad" times when insiders are exposed to unemployment, i.e. at times when they have more to gain from boosting job creation. ${ }^{15}$ These examples are illustrative of how political constraints may shape reforms. In Saint-Paul $(1993,2000)$, I have argued that in addition to its political feasibility, two-tier reforms may start political dynamics that are conducive to further reforms. Those who hold flexible, or temporary contracts, have different interests from those who hold rigid contracts, and if they become numerous enough, they can be used as a

\footnotetext{
${ }^{13}$ For example, the lower employment level brought about by that institution will only be reached gradually as firms do not replace voluntary quits. See Saint-Paul (2000, ch.9) for an analysis of politico-economic complementarities.

${ }^{14}$ These are analyzed in Saint-Paul $(1993,2000 \mathrm{ch}$. 8), from a political economy viewpoint. Economic analysis of these reforms include Bentolila and Saint-Paul (1992), Jimeno and Toharia (1993), Bentolila and Dolado (1994), and, more recently, Guell-Rottlan (2000), and Cahuc and Postel-Vinay (2002).

${ }^{15}$ Saint-Paul (1996).
} 
political constituency to implement further reforms. This is indeed what has taken place to some extent in Spain, where, a few years after having been introduced, temporary contracts accounted for one third of employment, and reforms reducing employment protection for workers with permanent contracts were implemented in the nineties, in exchange for further restrictions in the use of temporary contracts. By contrast, in France, Italy, and Germany, where temporary contracts are used to a lesser extent and account for only $10-15 \%$ of total employment, virtually no reform of employment protection for permanent workers took place.

\subsubsection{Can business-induced policies also harm employment?}

That experience brings an interesting question: can political constraints lead to reforms that are worse than no reforms? In the case of the two-tier system of employment protection, a number of authors ${ }^{16}$ have argued that it may be detrimental to employment and/or welfare, for example if it increases wage pressure by reducing the exposure of employed workers with permanent contracts, as workers with temporary contracts bear the burden of labor turnover. While one may dispute these views, let us discuss its implications. Assume a two-tier system of employment protection is indeed quite poor in terms of job creation. Then, the benefits of such an arrangement would only be indirect, in the form of the political support it generates for further reforms. But then, that would suggest that countries where the number of temporary contracts is too small to affect the balance of power should simply get rid of them, at least from the point of view of reducing unemployment. Why would then such reforms take place in the first place, except by mistake? In order to answer that, one needs to point out that the main force opposing insiders in the political design of labor market institutions is not the unemployed, who are unorganized and command little political influence, but rather employers. Thus, the question can

\footnotetext{
${ }^{16}$ See Bentolila and Dolado (1994), Cahuc and Postel-Vinay (2003).
} 
more fundamentally be reformulated as: can a reform be good for employers but detrimental for net job creation?

One can think of whole classes of examples of such policies. We know from the theoretical literature that a reduction if firing costs may reduce employment ${ }^{17}$; yet it unambiguously increases profits. Increases in total labor supply through immigration or subsidies to young or female worker's participation in the labor market are unlikely to reduce equilibrium unemployment but would benefit firms. In equilibrium, however, if firms freely compete to attract workers, increased profitability is eventually dissipated in a higher outside option for workers, i.e. higher welfare for the unemployed (see Saint-Paul 2000, ch. 2, for a formal result along these lines). Consequently, there is an in-built convergence of interests between the unemployed and firms as long as the latter freely compete to hire workers. In places where product market regulation hampers that mechanism, one may well see policies than benefit employers but not the unemployed. Thus, greater product market deregulation may by itself have had little impact so far, but it makes it more likely that labor market deregulation has positive effects on employment.

\section{$4.2 \quad$ Ideology}

One factor that has been overlooked in the debate about European labor market reform is the role of ideologies and representations about the functioning of the economy in shaping our beliefs about what should be done. In particular, while in the United States there is a well-defined "mainstream" in economics, with other approaches still existing but being marginalized, in a number of European countries one still typically considers that there are many competing schools that are equally worth. The combination of a given policymakers' preferred "school" and some emotional discourse about "helping people" may lead to wrong policies which will not cure unemployment. However, these policies are

\footnotetext{
${ }^{17}$ Bentolila and Bertola (1990), Bentolila and Saint-Paul (1994).
} 
not uniformly mistaken and often benefit some interest groups. These interest groups then gain from promoting the underlying "school" or ideology regardless of whether or not it is correct. Some examples may illustrate this point.

\subsubsection{Examples of popular beliefs and who benefits from them}

- The view that all unemployment is Keynesian and there is no such thing as a long-run equilibrium rate of unemployment, or that such rate is zero or very low, implies that the bulk of unemployment would eventually be eliminated by traditional fiscal and monetary tools, and this underlines much of the short-run Keynesian stimulation policies. Instead of recognizing the failure of such policies, as exemplified by the case of Japan, the advocates of such ideologies argue that macroeconomic stimulus has not gone far enough. Ironically, this view can in, fact be accommodated within mainstream economics: the "hysteresis" literature provides mechanisms by which a temporary demand shock may permanently affect the natural rate of unemployment (See Blanchard and Summers (1986); Gottfries and Horn (1987)). Yet, as argued by Layard et al. (1990), it is unlikely that persistence mechanisms are strong enough to explain high unemployment for 30 years. Incidentally, defenders of the "100 \% Keynesian" view scarcely refer to these mechanisms.

- The idea that an increase in wages will help reduce unemployment because it stimulates consumption is popular among union leaders, which often advocate wage increases in order to lift the economy out of a slump ${ }^{18}$. While such effect may exist, but only if workers save less than capitalists, any positive effect on employment is bound to be short-lived, while the long-term effects are likely to be negative. However, increasing wages benefits incumbent employees, provided their jobs are protected enough, regardless of its effect on aggregate consumption and employment.

\footnotetext{
${ }^{18}$ A typical example can be found in a txt from the French Union CGT, "Sortir du bourbier des bas salaires", http://www.construction.cgt.fr/communication/tracts/tractsalaires.doc
} 
- The "lump-of-labor" fallacy, which states that the total amount of work is fixed and can only be shared among those who want to work, has led to many misguided policies, such as pre-retirement to "make room" for the young, or working time reduction. These policies have been quite prominent in France but also have had some impact in the Netherlands, Germany, and Belgium. They are likely to have harmed employment, as recently shown by Crépon and Kramarz (2002). Potentially, however, some groups of workers may benefit, for example if such Malthusian policies shelter them from competition. While this remains much to be investigated, a theoretical analysis can be found in Marimon and Zilibotti (2000).

- Another ideology is the general scepticism, among many analysts and policy makers, about the allocative role of prices in general, and of wages in particular. Dismissing the common sense view that less labor is demanded when its price goes up amounts to dismissing all policies that would lead to reductions in wages, or in the total cost of labor, in order to create jobs. Such view may be supported by the difficulties one encounters when estimating such effects, especially with aggregate data ${ }^{19} ;$ careful empirical work, however, has made a rather convincing case that increases in labor costs reduce employment ${ }^{20}$, at least when starting from levels as high as those which prevail in European countries. The view that it does not, however, remains popular in some places, and again it benefits workers who are already employed and whose labor is substitute for the jobs that would be created by such reductions in labor costs.

- People also tend to be more confident about the direct effects of policies than about their indirect ones (Gersbach and Schniewind (2001)). While the impact effect of a given policy is easy to figure out and uncontrover-

\footnotetext{
${ }^{19}$ See Card and Krueger (1995).

${ }^{20}$ Laroque and Salanié $(2000,2002)$.
} 
sial, its general equilibrium effects are more difficult to understand and depend crucially on one's views about the underlying functioning of the economy. These views differ across people, and furthermore many voters lack the cognitive ability to develop them, which leaves them vulnerable to propaganda. If these effects are important, they will shape beliefs in ways rarely friendly to employment-enhancing reforms. Thus, the direct effect of a reduction in the minimum wage is to reduce the income of minimum wage earners; subsequent job creation only come later. The direct effect of reducing employment protection is that some workers will lose their jobs; the benefits in terms of job creation come later, and hinge on the firms' rational calculations taking into account the reduced cost of having to get rid of a worker in the future; reductions in the generosity of unemployment benefits impose "hardship" on the unemployed, but their beneficial effects on employment involve the complex process of wage bargaining; and so on.

\subsubsection{The logic: a labor demand example}

To understand how ideology may interact with political economy, it is interesting to illustrate these points with a simple example. Assume there are three categories of labor: skilled workers, for whom the labor market is perfectly competitive; medium skilled workers, and low-skill workers. Assume the medium-skilled workers are perfect substitutes for the low-skilled, but more productive. On the other hand, the high skilled workers are complementary with these two factors of production. Let us introduce a binding minimum wage $\bar{w}$, so that the least skilled are not fully employed. In equilibrium, their wage is precisely equal to the minimum wage; At the same time, the medium-skilled's wage will be larger, since they are more productive, by a constant factor equal to the ratio between their productivity and that of the unskilled. Finally, the minimum wage reduces the wage of the high skilled, since firms use less of the complementary inputs in 
production.

Clearly, an increase in the minimum wage benefits the medium-skilled, since their greater productivity guarantees that they remain at full employment ${ }^{21}$, and their wage is a multiple of the minimum wage, because of substitutability between them and the low-skilled. That is, a greater minimum wage increases the medium-skilled's income because it reduces competition between them and the low-skilled.

On the other hand, an increase in the minimum wage unambiguously harms the highly skilled, as the reduction in employment of the low-skilled, with whom they are complementary, lowers their productivity.

What about the welfare of the low skilled? An increase in the minimum wage raises the wage of those who are employed but increases the number of those who are unemployed. Assume that, at the time society decides on the level of the minimum wage, they do not know ex-ante whether they will be employed or not. In order to figure out which level of the minimum wage they favor, they will balance the marginal costs of a higher minimum wage in the form of reduced employment probability, against its marginal benefits in terms of higher wages for those who do find a job. Clearly, they are more likely to favor a high minimum wage, the lower its negative effect on the probability of being employed, i.e. the lower the elasticity of labor demand.

Suppose now that it is not known what the true parameters of the economy are. The high-skilled do not need to know them in order to form their preferences about a rise in the minimum wage, as they know they lose from it regardless of the parameters; similarly, the medium skill know that they gain regardless of the parameter, at least as long as one remains in the regime where some lowskilled are employed. The low-skilled, however, cannot tell whether they gain or lose absent any knowledge about the underlying parameters. Consequently, to the extent that the low-skilled's opinion matters to the actual policies that

${ }^{21}$ That is true as long as some low-skilled remain employed. 
are followed, it is in the interest of other groups to popularize views and theories about the value of these parameters, regardless of whether those views are rational or not. Thus, the medium skilled unconditionally benefit from the general belief that the elasticity of the demand for unskilled workers is quite low, or that wages play no allocative role, while the high skilled benefit from the opposite views.

More fundamentally, a belief which is unlikely to be correct (relative to possible alternative views) may be sustained if (i) the power to influence beliefs is not distributed the same way as political power (otherwise one can directly impose one's preferred policies rather than influence other's beliefs), (ii) the preferred policies of those groups who have a relatively high influence on beliefs is likely to be less responsive to knowledge about the economy's true underling parameters than the preferred policies of those groups who have a relatively high influence on outcomes ${ }^{22}$. Another key point is that a group need not know whether or not an ideology is correct and at the same time may know that it benefits from it.

One can think of a number of other plausible examples. For example, in order to buy the support of skilled workers, unions may convey the view that their policies redistribute between labor and capital, whereas in a world of international capital mobility they in fact redistribute between skilled and unskilled workers. ${ }^{23}$

\subsubsection{Influencing beliefs}

An important, related question that the economic analysis of ideology should then address is: by what means can a group manipulate the views of the lowskilled in order to convince them one way or another about the net effects of a minimum wage hike?

\footnotetext{
${ }^{22}$ In a democracy, these groups would be voters, and those political parties or interest groups that have a large impact on the media and the educational system, respectively.

${ }^{23}$ That example was suggested to me by Olivier Blanchard.
} 
One approach would be to believe that the low-skilled are rational Bayesian learners, and therefore are updating their beliefs on the values of the parameters on the basis of observed economic outcomes. In such a case, one may influence beliefs by manipulating either priors or posteriors. Manipulation of posterior beliefs can take place by a group who controls the government. If the low skilled's prior is favorable to the group which controls the government (for example if they believe in a low wage elasticity of unskilled labor demand and if the medium-skilled control the government), the government can put noise in the economy in order to slow the learning ${ }^{24}$. One way of doing so is to perturb the demand for labor (via volatility in public expenditure, for example), so as to prevent people from identifying economic parameters. This does not a priori resemble actual government practices. However, if we now consider that learning may take place cross-sectionally, by comparing, say, different segments of the labor market, then "noise" can show up as complex labor market policies with numerous special cases; in fact in many countries labor market regulations and policies exhibit such unnecessary complexity. The general point is: social groups who benefit from current priors gain from greater complexity to the extent that it prevents or slows learning about the economy's underlying parameters.

There is no consensus about how priors are formed, and when it comes to influencing them it may be irrelevant whether agents are rational or not. In both cases one has to know how beliefs are formed and why some beliefs are more popular than others, on which little is known. But neuroscientists, for example, have proved that statements that are often repeated tend to be believed regardless of the rational basis for considering them as true ${ }^{25}$. One may then expect that the high-skilled and the medium-skilled would compete with each other in sending repeated messages to the low-skilled, using the media and the education system.

\footnotetext{
${ }^{24}$ Similar effects have been studied in a different context by Alesina and Cukierman (1990).

${ }^{25}$ See Camerer et al (2003), Gilbert and Gill (2000).
} 
That beliefs that are unlikely to be grounded on knowledge of actual facts may have a large impact on policy is substantiated by a recent paper by PostelVinay and Saint-Martin (2003). Using socioeconomic surveys, they construct synthetic indicators, for a number of European countries, of worker's subjective assessment of their degree of job security. They find that countries where workers feel more insecure are countries where employment protection is stricter. Thus causality seems to run from people's perception to collective decisions about the level of employment protection. In this particular case, it is unlikely that differences in perceptions about job security originate in genuine differences in the underlying level of labour turnover. So it is possible that these perceptions are supported by ideologies and views expressed in the media and the educational system. To learn more about it, one would need to measure, for example, the weight given by the media to job destruction episodes in highly visible plants; the media's attention may also be caught by spectacular actions such as strikes, boycotts, etc.

Another piece of evidence is given by Blanchard and Philippon (2003), who argue that the degree of trust between labor and capital, if measured by strike activity, statistically explains part of the divergence between high and low unemployment countries. When trust is not present, unions do not believe firm's statements about labor costs, the employment effects of wage increases, and so on, and stick to their view of the world. Clearly, there is a two-way interaction between trust and ideology: unions will not trust firms' announcements if they strongly believe in an ideology which contradicts them; and they are more likely to believe an ideology that says that employment is unresponsive to labor costs if they discard contrary views by firms they don't trust.

Finally, let us point out that the methodological problems that plague social sciences create an opacity that can be taken advantage of by interest groups in order to promote their views. Since in most democracies, the public debate is informed by "experts", whose views are reported in the media, that issue should 
not be under-estimated. Let us give two telling examples in the French context.

In the context of the debate over working-time reduction, the lump of labor fallacy was repeatedly put forward, based on the casual observation that employment had remained constant throughout since 1975. Some politicians went as far as saying that working time reduction should occur repeatedly to offset secular productivity growth-that is, they moved from the 'lump of labor' to the 'lump of output' fallacy. A large number of macroeconometric studies were produced showing that working time reduction created a number of jobs during a given number of years, on the basis of short-run Keynesian models that were unsuitable for dealing with these kind of issues, given their very crude approach to wage formation and aggregate supply (and, by construction, they predicted a zero long-term effect of such policies on employment, hence a net reduction in GDP per capita). The debate conveyed to the public the false impression that "experts agreed that working-time reduction" created jobs.

In the other episode, which took place in 2000 , unions at the statistical administration protested against the publication in its journal, of an econometric study by two leading economists, Guy Laroque and Bernard Salanié, which showed that the French minimum wage destroyed jobs ${ }^{26}$. They insisted that there existed alternative studies pointing to an opposite conclusion, and pressured the management of that administration to state publicly that it did not endorse that study. ${ }^{27}$ That episode squares well with the above argument about uncertainties regarding the elasticity of labor demand. It shows that interest groups can intervene directly to manipulate the production and dissemination of knowledge. To the extent that such process increases uncertainty about the way the economy works, it also shows that these interest group's preferences are such that they benefit from that uncertainty. That is, knowing more is unlikely to affect their own preferred policies, but may affect the decisive voter's

\footnotetext{
${ }^{26}$ An english language version of their paper can be found in Laroque and Salanié (2002).

${ }^{27}$ The open letter sent by the unions (in French) can be read at the unions' web site: http://cgtinsee.free.fr/dossiers/etudes/Larosala.htm
} 
preferred policies in a way which is detrimental to them on average.

To summarize, different social groups want to influence beliefs in a way favorable to them. The outcome will depend on the distribution of power among those groups ${ }^{28}$, and there is thus no reason to expect the "truer" views of the world to prevail.

\subsection{Agency}

Another important issue is the existence of agency problems in implementing government policies. Economists often tend to assume that they may be implemented without obstacle as if the government were an integrated command structure similar to an army. But it is in fact replete with agency problems, in particular since in many countries the penalties that can be imposed on a civil servant for inappropriate behavior are lower than in the private sector (due to job security provisions, for example). Such agency problems are likely to influence the outcome of reforms, in a way which may change our assessment of which policies work and which don't.

For example, there is a general agreement among economists that a tight monitoring of the unemployed's job search activity is desirable. This leads to the following recommendation: rather than reduce social insurance by lowering unemployment benefits, just tighten eligibility requirements and stop paying benefits to those who turn down suitable jobs.

The problem is that the employment agency workers who are supposed to implement such policies may well fail to do so because they consider the unemployed, not the tax payer, as their clients. This is all too natural since it is the unemployed with whom they are in contact on a daily basis and since, on the other hand, there typically is no incentive mechanism for them to internalize the government's objective. It is all too easy, for example, to convince oneself that a job offer was "unsuitable" after all.

\footnotetext{
${ }^{28}$ It is conceivable that a minority group which has no political power may nevertheless command a privileged position in the media or in the educational system.
} 
One can get an idea of the magnitude of the agency problem by looking at the functioning of the unemployment agencies (or public employment services), in the related area of placement. There is a wide agreement that public services do a poor job at bringing unemployed workers and vacant positions together. A study by the OECD (1991) politely reports that "it seems likely that at least in many EC countries, many people becoming unemployed during the eighties were not contacted with any proposal to apply for a specific job during their first year of unemployment. For many unemployed people, this may carry 5.3(yEhl)-0.2(e)TJ0.5569-1.8922T) 
wage-setting) are in the low-unemployment club. ${ }^{29}$

From a theoretical perspective, centralizing all matches at a public service may yield welfare gains because of economies of scale and because that service could internalize congestion externalities exerted by participants on each other. However, there is no evidence of economies of scale (See Blanchard and Diamond (1989)), and, as Moen (1995) as shown, in the absence of economies of scale, profit-seeking competitive placement services correctly price congestion externalities, thus yielding an efficient outcome. In principle, one could well design incentives at the public employment service to mimic these outcomes. However, it looks that they have little incentives to match the unemployed to vacancies. One may speculate that it is because the bureaucratic logic indexes their resources on the stock of unemployed workers, rather than on the exit rate from unemployment. Here, political economy considerations may also be relevant: if the public employment service is managed by labor unions (as is the case in some countries, e.g. France), they have an interest in designing it so as to reduce competition between the employed and the unemployed; its monopoly coupled with its inefficiency may not be so surprising after all ${ }^{30}$.

Going back to the idea of imposing tighter monitoring of the unemployed's search effort, a well-intended reform that overlooks these issues may not only be ineffective but actually make things worse if one has to make concessions to buy the insiders' acceptance. For example, in 1999, the French employers' association managed to negotiate with a fraction of the unions a reform of the unemployment benefit system along these lines. Eventually, however, to get support from the (then left-wing) legislature and the other unions, the scheme had to be amended; in particular, the commitment asked from the unemployed worker evolved towards a bona fide pledge for job search, while at the same time the declining pattern of unemployment benefits with time was abolished. It is

\footnotetext{
${ }^{29}$ Since then, state monopoly of job placement services has ended in Austria, Denmark, Finland, Germany and Spain.

${ }^{30}$ See Saint-Paul (1998) for a political economy argument.
} 
not clear at all, then, whether the positive effects (on unemployment) of more intense job search will dominate the negative effects of the fact that benefits are no longer decreasing with time. If it is difficult for the government to make sure that workers at the employment agency adequately monitor job search, then it is preferable, if one wants to increase search intensity, to reduce benefits rather than implementing an inefficient monitoring scheme.

\section{Explaining divergence: research directions}

The preceding analysis has discussed a number of factors that may explain, in a given country, that reform has not taken place, or that it has been misguided. A tougher question is: can these factors explain the observed divergence among European countries in the 1990s? Ideally, one would like to show that in the low unemployment club, political constraints, agency constraints, or ideologies, were less important than in the high unemployment club. It would be bold to claim that is an established fact; the general problem is that there are only a handful of observations and that these countries differ in a number of dimensions. However, the preceding discussion can at least structure the discussion and provide avenues for future research on a few hypotheses that are likely to have some explanatory power.

1. Different shocks? One potential explanation is that the countries that have reformed have faced different shocks, that led them to different preferences regarding labor market rigidities, than other countries. There may be some truth to it; for example, there is some evidence that changes in employment protection legislation are affected by current business cycles conditions ${ }^{31}$. And some well-known reforms, like the Spanish liberalization of temporary contracts in 1984, seem to have been triggered by a situation of very high unemployment which forced insiders to make concessions. In principle, an economic environment which increases the exposure of employed workers to unemployment,

\footnotetext{
${ }^{31}$ See Saint-Paul (1996).
} 
should be helpful for reforms. Another factor increasing the drive for reforms is the existence of a fiscal crisis. Problems in financing unemployment benefits often force legislators to reduce their generosity (however, they typically also increase payroll taxers at the same time, so that the net effect on unemployment is unclear). Other financial problems of the welfare state, such as problems in funding public pensions or public health insurance, also may have spillover effects on labor market reforms, as they generate the need to increase employment, which is the tax base for these programs, and because savings in unemployment benefits may be used to ease fiscal problems elsewhere. The recent discussion of German reforms illustrates that point. The triggering factor is a fiscal crisis, and it has prompted the government to propose a wide package of reforms, including a number of labor market liberalizations. How much of the package will actually be implemented is not clear at this stage ${ }^{32}$. But this type of episode illustrates how transfers from the employed to the inactive increase the former's incentives to forego some protection in exchange for higher employment, as does the employed's increased exposure to unemployment.

This being said, it is unlikely that different shocks can explain all of the stark divergence across European countries with respect to the evolution of unemployment and labor market institutions. Business cycles are pretty similar and synchronized across these countries, and so are the financial problems faced by their welfare states.

2. The Euro? A related factor is whether or not a country belongs to the Euro area. There seems to be a correlation between that and a country's ability to reduce unemployment in the late nineties. The three non-Euro countries in the EC, Denmark, Sweden, and the UK, are all in the low unemployment club. In addition, Switzerland, which is not a member of the EU but belongs to a similar arrangement (the European Economic Area), has maintained a low unemployment rate throughout. In the medium run, not belonging to the Euro

\footnotetext{
${ }^{32}$ See EEAG (2004) for a description and tentative assessment.
} 
may be helpful since it allows to cope with shocks by devaluing the exchange rate. But we know that countries faced shocks that were not very asymmetric and that the benefits of devaluations are not very long-lived. However, having control over one's own exchange rate can be very useful in boosting a reform's political acceptability. A number of labor market reforms have short-run costs (wage losses for workers who have rents, employment losses for protected workers, etc.), and benefits that only materialize in the longer run. Using macroeconomic stimulus to accompany a reform can therefore be very useful to alleviate these short-run costs ${ }^{33}$. Belonging to the Euro shuts down one instrument of macroeconomic stimulus, monetary policy, and that may deter reforms unless they are coordinated among Euro countries. While that argument is correct in principle, it probably bears little relationship to the actual experience of European countries in the nineties; the non-Euro countries do not seem to have had a clearly more expansionary policy than the Euro countries. A Euro country like Ireland did well at implementing reforms and reducing unemployment. While some elements of reforms are contractionary in the short run (reductions in benefits deregulation of employment protection), others such as cuts in labor taxes are expansionary (and improve competitiveness just like a devaluation). A balanced package of both types of reforms maintains macroeconomic equilibrium, which allows to do away with monetary stimulus ${ }^{34}$.

3. Path dependence? Another hypothesis is that countries in the high unemployment club did fewer reforms because of greater status-quo bias. To go beyond tautology, one would have to investigate the reason for such differences. The above analysis suggests that higher employee rents are a source of statusquo bias; that could be a productive research directions. However, that idea is not consistent with the measure of rents reported in section 3: the countries with lower rents do not match those in the low unemployment club; but these

\footnotetext{
${ }^{33}$ See Bean (1998) and Saint-Paul and Bentolila (2001) for an analysis.

${ }^{34}$ However, in the future belonging to EMU may still deter structural reforms for countries that want to deregulate their labor markets without reducing the size of their welfare state, in which case a reduction in labor taxes would be difficult.
} 
data were not constructed to be made comparable across countries.

4. Small vs. big? It seems that smaller, more open economies have had an easier time implementing reforms than larger ones. Out of the $5 \mathrm{EU}$ countries with 40 million inhabitants or more, 4 are in the high unemployment club; of the remaining 10, only 3 are in the high unemployment club. This may be understood in political economy terms. Clearly, there is more scope for raising one's own wage at the expense of others in a large, closed economy, than in a small, open one. In a small economy, specialized in producing only a few products, the relative price of a good is pinned down by international prices which also create a force for factor price equalization. Thus the scope for redistribution between different categories of workers by manipulating prices (which is what labor market rigidities achieve), is much more limited. In contrast, one should expect more direct fiscal redistribution as a substitute. This is indeed what the experience of Scandinavian countries suggests.

5. Latin vs. "Anglo-Saxon"? Countries that have been successful in reducing unemployment typically belong to Anglo-Saxon (or Nordic) cultures, while Latin (or Southern European) countries still live with high and persistent unemployment. If one considers the following list of six countries: Portugal, Spain, Italy, France, Belgium, and Greece as defining the latter group, then five of them are in the high unemployment club. Only two of the remaining nine countries are in the high unemployment club.

A first, popular explanation, is that employment is more socially acceptable ${ }^{35}$, in "Latin" countries. One aspect is that the unemployed have an easier time in "Latin" countries because the family still acts as a safety net. That may well be true, but it remains, however, much more a stereotype than an established fact. And why does not see why the generous welfare states of many Nordic countries should not make it equally acceptable there.

Another possibility is that there is more political resistance to reform in

\footnotetext{
${ }^{35}$ See Bentolila and Ichino (2003), for an analysis.
} 
Southern European countries. In particular, one may argue that "counterproductive" ideologies have more influence in "Latin" countries. Casual evidence from the prevalence of various economic "schools of thought" and from the way economics is taught suggests that it is the case. One may then wonder why. This surely has to do with the fact that Marxist parties have had more support in France, Italy, Spain and Portugal than elsewhere. But that leaves us with no explanation as to why people have different views of the world in different countries, and, more problematically, why there is so little learning from successful countries.

One potentially productive research direction is to explain that discrepancy in terms of multiple equilibria; i.e. there may exist several self-sustaining beliefs about the underlying functioning of the economy ${ }^{36}$. Even if one manages to make such an argument, one must then explain how equilibrium selection has to do with "culture". Another research direction, popularized by La Porta, Lopez de Silanes, and Shleifer, insists on the role of legal origins. In a recent paper, joint with Djankov and Botero (1993) they show, using a cross-section of countries, that countries with French legal origins tend to regulate labor market more than common law countries. The puzzle is: why are legal origins so important? They cannot be interpreted as a proxy for "culture", because their effects are identified by comparing groups of countries with similar legal origins but very different cultures. One promising hypothesis, in the line of the mechanisms discussed here, is that legal origins have shaped priors; for example, if markets are not left to operate freely, there is less room for learning about how well they work.

\footnotetext{
${ }^{36}$ See Piketty, 1995, for an argument among those lines in another context.
} 


\section{Conclusion}

A new stylized fact that labour economics and macroeconomics have to explain is the sharp divergence, since 1990, between those European countries that managed to get out of the unemployment problem and those who are stuck with it. The evidence suggests some proximate causes for that divergence, since successful countries typically have implemented a number of labor market reforms. As this validates the "orthodox" view that rigidities are an important cause of unemployment, one important implication is that it is unlikely that in the future growth or a boom will persistently reduce unemployment in those countries that have failed to reform so far. As for the deeper causes of why some countries have reformed and others not, much remains to be understood and we hope to have provided some interesting research directions; as the last section suggests, political economy considerations, in connections with beliefs and the economic environment, seem to play a role in explaining the geographical patterns of reform. 


\section{REFERENCES}

Alesina, Alberto and Alex Cukierman, (1990), "The Politics of Ambiguity", Quarterly Journal of Economics v105, n4 (November 1990): 829-50

Bean, Charles R. (1994), "European Unemployment: A survey", Journal of Economic Literature, v32, n2 (June 1994): 573-619 - (1998), "The Interaction of Aggregate-Demand Policies and

Labour Market Reform", Swedish Economic Policy Review v5, n2 (Autumn 1998): $353-82$

Bentolila, Samuel, and Giuseppe Bertola (1990), "Firing Costs and Labour Demand: How Bad Is Eurosclerosis?", Review of Economic Studies v57, n3 (July 1990): 381-402

Bentolila, Samuel, and Gilles Saint-Paul (1992), "The macroeconomic impact of flexible labor contracts, with an application to Spain", European Economic Review , and (1994), "A Model of Labor Demand with Linear Adjustment Costs", Labour Economics v1, n3-4 (September 1994): 30326

Bentolila, Samuel, and Andrea Ichino (2003), "Unemployment and Consumption: Why Are Job Losses less Painful than Expected near the Mediterranean?" . mimeo, January 2003

Bentolila, Samuel, and Juan Dolado (1994), "Labour Flexibility and Wages: Lessons from Spain (with Juan J. Dolado)" Economic Policy, 18, 1994.

Blanchard, Olivier and Thomas Philippon (2003), "The decline of rents, and the rise and fall of European unemployment", mimeo, MIT

Blanchard, Olivier, and Summers (1986), "Hysteresis and the European Unemployment Problem", NBER Macroeconomics Annual

Blanchard, and Summers (1988), "Beyond the natural rate hypothesis", American Economic Review

Blanchard, Olivier and Wolfers, "The Role of Shocks and Institutions in the 
Rise of European Unemployment: The Aggregate Evidence", Economic Journal v110, n462 (March 2000): C1-33

Blanchard, Olivier, and Peter Diamond (1989), "The Aggregate Matching Function", National Bureau of Economic Research Working Paper: 3175

Bruno, Michael, and Jeffrey Sachs (1985), The economics of worldwide stagflation, Harvard U. Press

Cahuc, Pierre, and Fabien Postel-Vinay (2002), "Temporary Jobs, Employment Protection and Labor Market Performance", Labour Economics, (9)1 p. 63-91

Calmfors, Lars,Anders Forslund and Maria Hemström, "Does Active Labour Market Policy Work? Lessons from the Swedish Experiences", Swedish Economic Policy Review, 2001:2.

Camerer, Colin, George Loewenstein and Drazen Prelec (2003), "Neuroeconomics: How neuroscience can inform economics", Working Paper, CalTech, 2003

Cohen, Daniel (1999), "Welfare differentials across French and US labor markets: a general equilibrium interpretation", CEPR discussion paper 2114.

Davis, Steven, John Haltiwanger and Scott Schuh (1996), Job creation and job destruction, MIT Press

Card, David, and Alan Krueger (1995), Myth and Measurement: The New Economics of the Minimum Wage. Princeton: Princeton University Press

Crépon, Bruno, and Francis Kramarz (2002), "Employed 40 Hours or NotEmployed 39: Lessons from the 1982 Mandatory Reduction of the Workweek", Journal of Political Economy

Djankov, Simeon, Rafael La Porta, Florencio Lopez-de-Silanes, Andrei Shleifer, Juan Botero (2003), "The regulation of labor", NBER WP 9756

EEAG (2004), Third annual report of the European Economic Advisory Group at CES-Ifo.

Gersbach, Hans, and Achim Schniewind, (2001) "Learning of General Equi- 
librium Effects and the Unemployment Trap", Heidelberg University Working paper.

Gilbert, Daniel T. and Michael Gill, (2000), "The momentary realist", Psychological Science, 11, 394-398

Gottfries, Nils \& Horn, Henrik, (1987) "Wage Formation and the Persistence of Unemployment," Economic Journal, Vol. 97 (388) pp. 877-84

Güell-Rotllan, Maïa (2000), "Fixed-term Contracts and Unemployment: an Efficiency Wage Analysis", Industrial Relations Section, Princeton University, Working Paper n. 433.

Jimeno, Juan, and Luis Toharia (1993), "The Effects of Fixed-Term Employment on Wages: Theory and Evidence from Spain", Investigaciones Económicas, vol XVII

Heckman J.J., LaLonde, R.J. and Smith, J.A. (1999), The economics and econometrics of active labor market programs, in O.C. Ashenfelter and D. Card(eds.), Handbook of Labor Economics, Vol. 3A, Elsevier Science B.V., Amsterdam.

Laroque, Guy and Bernard Salanié, (2000)," Une décomposition du nonemploi en France ", Economie et statistique, 331

Laroque, Guy and Bernard Salanié (2002), "Labor Market Institutions and Employment in France", Journal of Applied Econometrics (2002), 17, 25-48.

Layard, Richard, Steven Nickell, and Richard Jackman (1990), Unemployment. Oxford: Oxford U. Press

Marimon, Ramon, and Zilibotti, Fabrizio (2000), "Employment and distributional effects of restricting working time" European Economic Review, Volume 44, Issue 7, pp. 1291

Moen, Espen (1995), "Competitive search equilibrium", Journal of Political Economy v105, n2 (April 1997): 385-411

Nickell, Steven (2003), "Labour market institutions and unemployment in OECD countries" CES-Ifo DICE Report, 2, 2003. 
Orszag, Michael, and Dennis Snower (1998), "The Anatomy of Policy Complementarities", Swedish Economic Policy Review, 5(2).

Piketty, Thomas, (1995) "Social Mobility and Redistributive Politics", Quarterly Journal of Economics

Saint-Paul, Gilles (1993), "On the political economy of labor market flexibility", NBER Macroeconomics Annual

(1995) "The high unemployment trap", Quarterly Journal of Economics

(1996), "Exploring the political economy of labor market institutions", Economic Policy

(1997), "The rise and persistence of rigidities", American Economic Review, May

- (1998), "A framework for analyzing the political support for active labor market policy", Journal of Public Economics

(2000), The political economy of labour market institutions.

Oxford: Oxford University Press

- (2002), "The political economy of employment protection",

Journal of Political Economy

- (2003), "Are European labor markets becoming more com-

petitive? Evidence from measured worker rents", paper prepared for the Central Bank of Chile annual conference

Saint-Paul, Gilles and Samuel Bentolila (2001), "Will EMU increase Eurosclerosis?" in Ch. Wyplosz, ed., The Impact of EMU on Europe and the Developing Countries, Oxford University Press. 